\title{
Construction of Enterprise 5G Business Ecosystem: Case Study of Huawei
}

\author{
Yan Li, Tianzhu Li \\ School of Business Administration, University of Science and Technology Liaoning, Anshan, China \\ Email: ikun1996@163.com
}

How to cite this paper: Li, Y., \& Li, T. Z. (2021). Construction of Enterprise 5G Business Ecosystem: Case Study of Huawei. American Journal of Industrial and Business Management, 11, 92-110.

https://doi.org/10.4236/ajibm.2021.111007

Received: December 28, 2020

Accepted: January 19, 2021

Published: January 22, 2021

Copyright $\odot 2021$ by author(s) and Scientific Research Publishing Inc. This work is licensed under the Creative Commons Attribution International License (CC BY 4.0).

http://creativecommons.org/licenses/by/4.0/

\begin{abstract}
Existing research does not explain the construction of the $5 \mathrm{G}$ business ecosystem at the enterprise level. Using the method of case study, through the analysis of the development and structure of Huawei $5 \mathrm{G}$ business ecosystem, we explore the construction model of enterprise 5G business ecosystem. On this basis, three experiences such as clear risk permutation and combination, accurate positioning of the enterprise and replace the business ecosystem, are proposed to give some inspirations for enterprises to build 5G business ecosystem. The main contribution is of reference value for the benign operation of $5 \mathrm{G}$ enterprises, and of practical significance for the development of $5 \mathrm{G}$ industry and enterprise innovation.
\end{abstract}

\section{Keywords}

5G, Business Ecosystem, Case Study

\section{Introduction}

Based on growing demand for mobile data on the Internet, 5G technological innovation and its industrial development have attracted wide attention from all walks of life. In June 2019, the Ministry of Industry and Information Technology issued 5G commercial licenses to China Telecom, China Mobile, China Unicom and China Radio and Television, China officially entered the first year of 5G commercial use $(\mathrm{Xu}, 2019)$. 5G will become an important catalytic factor for comprehensive formation of Internet of Things, accelerating transformation from mobile Internet to mobile Internet of Things. The collaboration and mutual shaping between $5 \mathrm{G}$ and Internet of Things will start to bring revolutionary changes to economy and society (Palattella et al., 2016). The epoch-making significance of $5 \mathrm{G}$ opens up a new space for innovation in current market. Enterprises should keep up with the pace of times and build a business ecosystem with 
matching degree and correlation degree in order to win the opportunity in 5G competition.

Rather than competition between enterprises, it is more reasonable to express the competition between enterprises in business ecosystem. Enterprises reduce the cost and risk of industrial chain through internal system management and external resource allocation, which are good to enhance the reserve of competitiveness and accelerate the pace of development. For example, Xiaomi chose ecosystem construction of smart hardware ecological model to achieve value fission after experiencing trial and error of enterprise expansion model (Tan et al., 2019); Apple responded to dynamic changes of consumer market and captured the needs of consumers to form business ecosystem in which enterprise itself is core (Liu \& Xiong, 2013); Both structure and technological development are integrated by Alibaba to form derivative business such as terminal and then Alibaba established a business ecosystem (Tong \& Yang, 2019). Academia has studied the evolution of corporate business ecosystem from different perspectives (Anggraeni et al., 2007). For example, Jingdong captured opportunities and needs in earlier stage, integrated organization in midium-term, and then released its platform advantages in later period. The improvement of business ecosystem presented a win-win situation (Zhang et al., 2018). Wind turbine enterprises in China have built a wide range of international licensing network and domestic cooperative relationship from capacity accumulation (Chen et al., 2014).

However, there is still a lack of research on $5 \mathrm{G}$ business ecosystem, especially at enterprise level. There is no complete framework for enterprise $5 \mathrm{G}$ business ecosystem. Aiming at the deficiencies of existing research and the rapid development of $5 \mathrm{G}$ industry, the paper selects Huawei as a research case to explore the process of building enterprise $5 \mathrm{G}$ business ecosystem, and sublimates theoretical model and management enlightenment, which will help improve the reference value of $5 \mathrm{G}$ industry development and enterprise innovation.

\section{Research Design}

\subsection{Theoretical Summary}

Moore (1993) drew a new metaphor of competition from the study of biological and social systems, and first proposed the concept of business ecosystem. He believes that business ecosystem that participating members work together to benefit mutually is an economic consortium based on the interaction of organizations and individuals. Most companies in business ecosystem adopt competition and cooperation to create the best economy and quality products or services that meet the needs of customers (Moore, 1993). Scholars such as Lansiti \& Levien (2004) further point out that business ecosystem connects an interactive network structure to reduce the risk of system. The health of system is determined by overall operation level (Lansiti \& Levien, 2004). Specifically, business ecosystem is a networked organization around core technologies, in which participants are at stake with each other. The explicit mode of interdependence between partici- 
pants is an essential feature of dividing business ecosystem and departments, that is, when a participant leaves the system, the benefits of other participants are weakened; when a new participant enters the system, the benefits of all participants increase. Each element member has to bear an unknown future (Hartigh et al., 2006).

There are three theoretical perspectives regarding the evolution of business ecosystem. One is the perspective of biological ecosystem. This is the initial stage of business ecosystem. Just as the survival of species depends on sunlight, water and soil nutrients in natural resources, business ecosystem is born in original whirlpool of capital, customer benefits and talents generated by innovation from the perspective of ecological equivalents (Moore, 1996). The second is business model perspective. This is the growth stage of business ecosystem. Some scholars believe that business model (implicit and explicit) is a new unit of analysis. The scope of company-centric business model should be broader than company's business scope. It emphasizes explain value creation and value acquisition (Zott et al., 2011). The third is the perspective of innovation ecosystem. This is the evolution stage of business ecosystem to a higher level. Innovation ecosystem is a more complex ecosystem (Sun \& Wei, 2019). Innovation changes participants, environment and boundaries, which defines the boundaries of ecosystem (Ritala \& Almpanopoulou, 2017). The components of bio-ecosystem are inconsistent with enterprise and business model framework is not comprehensive enough, this article applies the perspective of innovation ecosystem compared with business model and biological ecosystem, which can better reveal the commercialization of enterprises.

Innovation is the only sustainable source of competitive advantage for enterprises, but innovation cannot evolve in a vacuum. Enterprises need to gather funds, customers and many other elements, seizing opportunities to gather strength to achieve value creation. In $5 \mathrm{G}$ era, business ecosystem plays a more prominent role in corporate innovation and competitive advantage. However, existing literature lacks corresponding research on construction, evolution, and structure of corporate $5 \mathrm{G}$ business ecosystem.

\subsection{Research Method}

In theoretical construction, case study has become an increasing popular strategy, which forms the basis of a large number of studies (Eisenhardt \& Graebner, 2007). Comprehensive theoretical construction, theoretical sampling of cases, unbiased interviews, abundant evidence in tables or appendices and clear theoretical arguments bridge from qualitative evidence to mainstream deductive research, they are the characteristics of case study. Case study is usually regarded as useful tool for exploring research projects, it can describe the nature of things and explore overall evolutionary development of things. Case study is suitable for new or relatively weak research fields or in-depth investigation of a specific and complex case of real world (Rowley, 2002; Yin, 2013). This article studies the 
evolution of 5G enterprise business ecosystem, involving how enterprises build $5 \mathrm{G}$ business ecosystem and the cooperation within $5 \mathrm{G}$ business ecosystem. Considering that the relationship between business ecosystem construction is more complicated, case study method is a suitable choice. In specific research process, we use a descriptive single case study method to discuss $5 \mathrm{G}$ business ecosystem of Huawei through detailed description of practical activities, showing the growth process of $5 \mathrm{G}$ business ecosystem from shallow to deep over time and abstracting inductive theory laws.

\subsection{Research Case and Data Collection}

In accordance with typical and extreme requirements of case study, we screened multiple cases and finally determined that Huawei was the subject of this case study. The main reasons are the following three. First, as the leader of Chinese private enterprises, Huawei is the world's leading provider of information and communication technology (ICT) solutions, and has built an integrated pattern of cloud platform, industrial application and intelligent terminal. Secondly, Huawei not only has outstanding R\&D capabilities and numerous patents in 5G network, but it also has manufacturing capabilities that other companies cannot match, making it a place in 5G industry. Finally, Huawei has been focusing on polishing business ecosystem. Its internal structure has been adjusted by trial and error, and its revenue model has been improving, showing a positive corporate trend which has a strong reference value for $5 \mathrm{G}$ related enterprises. The materials we used to construct the case mainly include annual reports obtained through public channels, various academic papers, media reports and information published on the official website of Huawei (as shown in Table 1). According to the "triangular verification" thinking model, information from different sources is compared to achieve mutual verification between the logic of data and information, so as to maximize the credibility of the research.

\section{Case Introduction}

In 1987, Huawei Technologies Co. Ltd was established in Shenzhen, Guangzhou. From early production of communication equipment to the complete layout of communication equipment business for operators, cloud services for enterprises and consumer services for terminals, Huawei business scope has continued to expand in the 30 years since its establishment. In 2009, Huawei began a planned layout of $5 \mathrm{G}$ technology. The specific development process is shown in Figure 1.

Table 1. Data source table.

\begin{tabular}{|c|c|c|c|}
\hline Data source & Official website of Huawei & Media coverage & Academic research achievements \\
\hline $\begin{array}{l}\text { Data } \\
\text { content } \\
\text { listing }\end{array}$ & $\begin{array}{l}\text { Major events and decision-making } \\
\text { content that Huawei has participated in } \\
\text { at different stages of } 5 \mathrm{G} \text {, such as the } \\
\text { establishment of } 5 \mathrm{G} \text { innovation research } \\
\text { centers in } 9 \text { countries in } 2014 \text {. }\end{array}$ & $\begin{array}{l}\text { Mainstream media's interviews with } \\
\text { Huawei's management and reports on } \\
\text { Huawei's 5G-related press conferences, } \\
\text { such as huawei's Products and Solutions } \\
\text { Press conference in London } 2020 \text {. }\end{array}$ & $\begin{array}{l}\text { Search the research results of mainstream } \\
\text { journals on Huawei, such as the article } \\
\text { "The Importance of } 5 \mathrm{G} \text { and China's } \\
\text { Catching up Opportunity" published by } \\
\text { People's Forum. }\end{array}$ \\
\hline
\end{tabular}




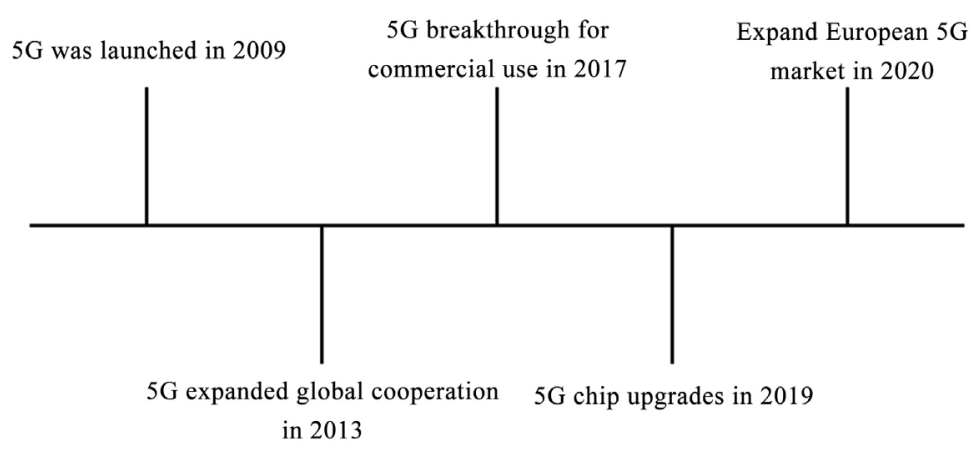

Figure 1. Timeline of Huawei 5G major events.

In 2009, Huawei used a mathematical paper on polarization code published by Turkish professor Arikan as theoretical basis (Arikan, 2009), invested 600 million dollars to start. In order to conduct 5G basic technology research, research department has established a team of thousands of people engaged in decoding research and development, and 5G core research and development center was established in North America. In 2011, "2012 Laboratory" was born, which fully supported $5 \mathrm{G}$ products in terms of materials and technologies such as heat dissipation, ice and snow protection, and corrosion resistance. For example, the "Advanced Thermodynamics Research Laboratory" focused on solving the overheating problem of RUU product chips assembled with multiple modules to ensure the operating frequency of high-performance products that are differentiated from low-performance products. In 2012, Huawei, as a member of core management team, established METIS project alliance and worked with European partners to provide a strong support platform for the development of $5 \mathrm{G}$ system and technology.

In 2013, Huawei released 5G white paper and formed close joint research relationships with more than 20 universities around the world, including St Petersburg University, the University of Surrey and Shanghai Jiao Tong University in multiple fields. By 2014, Huawei had established 5G innovation research centers in the United States, Germany, Japan and other countries. Huawei joined Japanese 5GMF to jointly formulate $5 \mathrm{G}$ development plans and cooperated with multinational operators. In 2015, Huawei was deeply involved in 5G-MoNArch, and its $5 \mathrm{G}$ industry cooperation made positive progress in North America, Europe and China, Huawei took responsibilities among multiple international associations and alliances. Since 2016, Huawei has worked hand in hand with multinational operators such as Telefonica and Telkomsel in Indonesia, taking another big step on the road to $5 \mathrm{G}$ deployment and operation.

With the increasing maturity of $5 \mathrm{G}$ technology and the acceleration of base stations, Huawei $5 \mathrm{G}$ commercial volume has continued to make breakthroughs. $5 \mathrm{G}$ has entered the commercial journey from previous technology investment to value acquisition. In 2017, Huawei, an important member of IMT-2020 (5G) China Evaluation Group, was the first to complete the second phase of Chinese 5G technology research and development trial. In 2018, Huawei launched a full range of $5 \mathrm{G}$ product solutions that are supporting "end-to-end". By the end of 
2019, Huawei had launched world's first 5G multi-mode terminal chip named "Balong 5000", and had began to cooperate with operators to expand mobile broadband services, applications in 5G HD video and AR/VR. Huawei kept in line with consumer demand and continued testing in multiple scenarios to ensure commercial quality. In 2020, Huawei has won $915 \mathrm{G}$ commercial contracts, this number far surpassed competitors such as Ericsson and Nokia, ranking first in the world. Huawei continues to expand European market by setting up a highly automated wireless product factory in France to produce wireless communication equipment for European market. This is a major breakthrough in 5G European market.

\section{Case Analysis}

\subsection{The Formation Process of Huawei 5G Business Ecosystem}

The business ecosystem of Huawei changes with the change of strategic policy. In order to meet the needs of $5 \mathrm{G}$ industry innovation, Huawei has carried out continuous transformation, reorganization, and has optimized its organization to build a corresponding business ecosystem. For the convenience of narration, we divide the growth process of Huawei 5G business ecosystem into three dynamic processes: Huawei initial trial period of 5G from 2009 to 2012, Huawei 5G expansion and development period from 2013 to 2017, and Huawei mature and upward phase of $5 \mathrm{G}$ from 2018 to the present, as shown in Table 2.

1) Preliminary testing period. Huawei initially focused on the development of single technology and explored the formulation of $5 \mathrm{G}$ standards in practice, among which the "2012 Lab" platform helped Huawei in the initial stage of 5G. On the one hand, Huawei increased the training of $5 \mathrm{G}$ technical teams and the investment of $5 \mathrm{G}$ R\&D funds. Resource and capital helped to promote research and development of 5G technology. On the other hand, it accelerated the global layout of $5 \mathrm{G}$ research centers and built a unique and innovative $5 \mathrm{G}$ ecosystem featuring win-win cooperation. Canadian study center, for example, gathered excellent scientists and engineers with great concentration of 5G chip development and standards at home and abroad. Huawei relied on technology and information reserves in communication industry for many years, and cooperated with many partners to promote the process of 5G. In anticipation of the possibility that $5 \mathrm{G}$ would become a basic social network in the future, Huawei began to accumulate energy and invested various resources such as human and financial resources to accelerate research and development process, preliminarily establishing the industry leading edge (Figure 2).

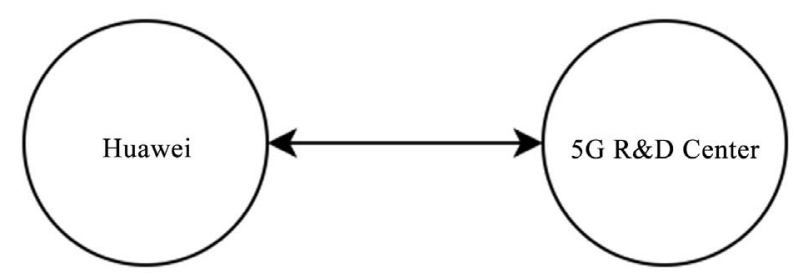

Figure 2. Huawei 5G business ecosystem in initial trial period. 
Table 2. Growth process and characteristics of Huawei 5G business ecosystem.

\begin{tabular}{llll}
\hline & Test period & Extended development period & Mature period \\
\hline $\begin{array}{l}\text { Research and } \\
\text { development of 5G }\end{array}$ & $\begin{array}{l}\text { The initial research } \\
\text { and development }\end{array}$ & $\begin{array}{l}\text { In-depth research and } \\
\text { development }\end{array}$ & $\begin{array}{l}\text { Focus on research and } \\
\text { development }\end{array}$ \\
5G product & 5G has fewer patents & $\begin{array}{l}\text { 5G patents rank top in } \\
\text { the world }\end{array}$ & $\begin{array}{l}\text { 5G patents rank first in } \\
\text { the world }\end{array}$ \\
5G corporation & $\begin{array}{l}\text { A handful of R\&D } \\
\text { centers }\end{array}$ & $\begin{array}{l}\text { Most universities and } \\
\text { organizations }\end{array}$ & Multi-field, all-round \\
\hline
\end{tabular}

Source: Compiled by the author.

2) Expansion development period. As $5 \mathrm{G}$ leader, Huawei has continuously expanded the scale of $5 \mathrm{G}$ research and cooperation during this period, such as cooperating with top universities and organizations all over the world, joining a number of international organizations and projects and strengthening international exchanges. The number of $5 \mathrm{G}$ key patent technologies owned by Huawei ranks among the best in the world. Huawei has always been a global leader in definition and promotion of 5G. During this period, it was emphasized that in-depth innovative "vertical industry win-win" ecological strategy should be adopted. Appropriate 5G technology and standards should be matched under the circumstances of different demands. Specifically, communications industry should not only focus on inter-industry cooperation, but also promote the establishment of cross-industry communication platforms. Under the premise of continuous research and development, Huawei has begun to cooperate with strategic partners such as operators and equipment vendors, looking for the pain points of different customer groups, providing more comprehensive products and services. Gradually Huawei expanded the scope of enterprise 5G business ecosystem. For example, Huaguang Technology is an important supplier of Huawei $5 \mathrm{G}$ optical modules and it is one of the first suppliers of Huawei 5G base station construction. Keysight Technology is a company that mainly produces measuring instruments and software, assisting Huawei in completing the second phase of 5G technology testing. Huawei 5G business ecosystem was improving day by day in cross-industry cooperation (Figure 3 ).

3) Rise in maturity. Huawei has tested in $5 G$ technology, standard, chip, network, terminal and other fields, leading 5G technology to a new level of speed and stability. Since 2018, Huawei has put forward 5G proposition of industry leading, technology leading and experience leading. 5G microwave starts a new journey for full commercial use. $5 \mathrm{G}$ entered the stage of productization. Huawei $5 \mathrm{G}$ mobile phones and base stations were important embodiment of the commercialization of baseband chip technology. Promoting 5G commercialization can accelerate completion of $5 \mathrm{G}$ technology research and development, and promote further maturity of ecosystem of chip, component, and terminal. During this period, Huawei $5 \mathrm{G}$ ecological strategy was classified into specific products to select partners. As core enterprise, a clear strategic goal of building business ecosystem is compatible with 5G-related enterprises (equipment vendors, operators, etc.) and users. For example, 5G mobile phones used Huawei 
self-developed baseband chips named Barong 5000 and Kirin 980. Huawei cooperated with BYD Electronics, Goertek and other companies in professional field. Precision filters (Luxshare) and high-frequency and high-speed (Shengyi Technology) substrates had also been gradually incorporated into Huawei's base station supply system. Although commercial process of $5 \mathrm{G}$ has just begun, Huawei has already become a leader in the industry based on the accumulation of more than ten years of core technology. At present, Huawei $5 \mathrm{G}$ basic patents are ranked first in the industry, and its optical transmission technology is the world's leading (Figure 4).

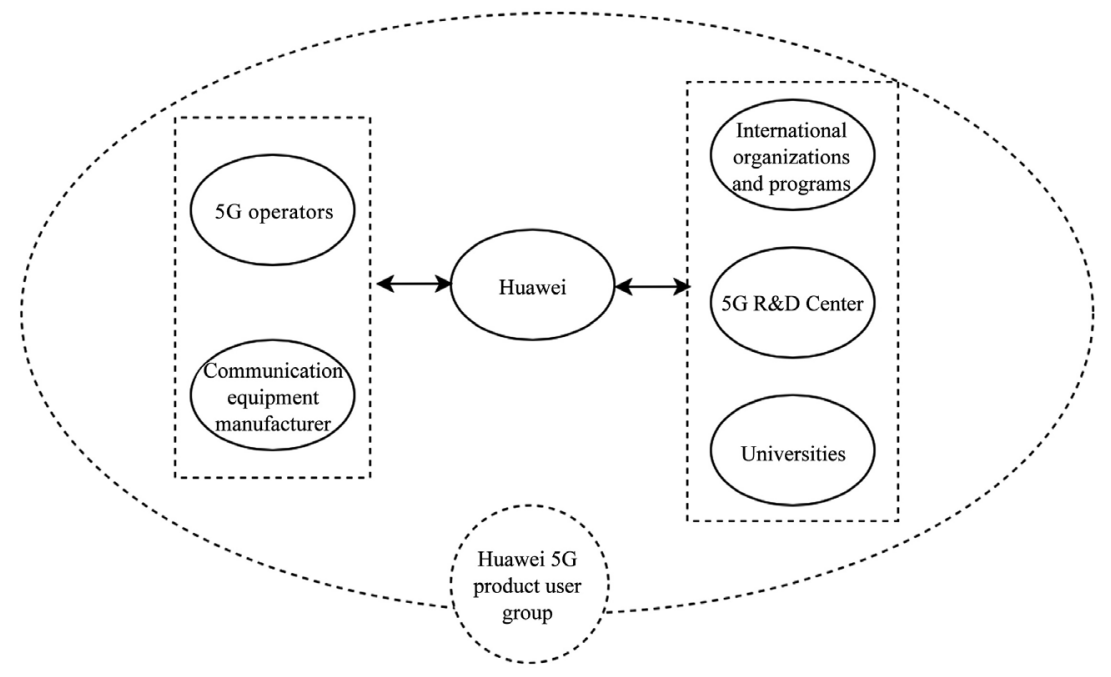

Figure 3. Huawei 5G business ecosystem in expansion and development period.

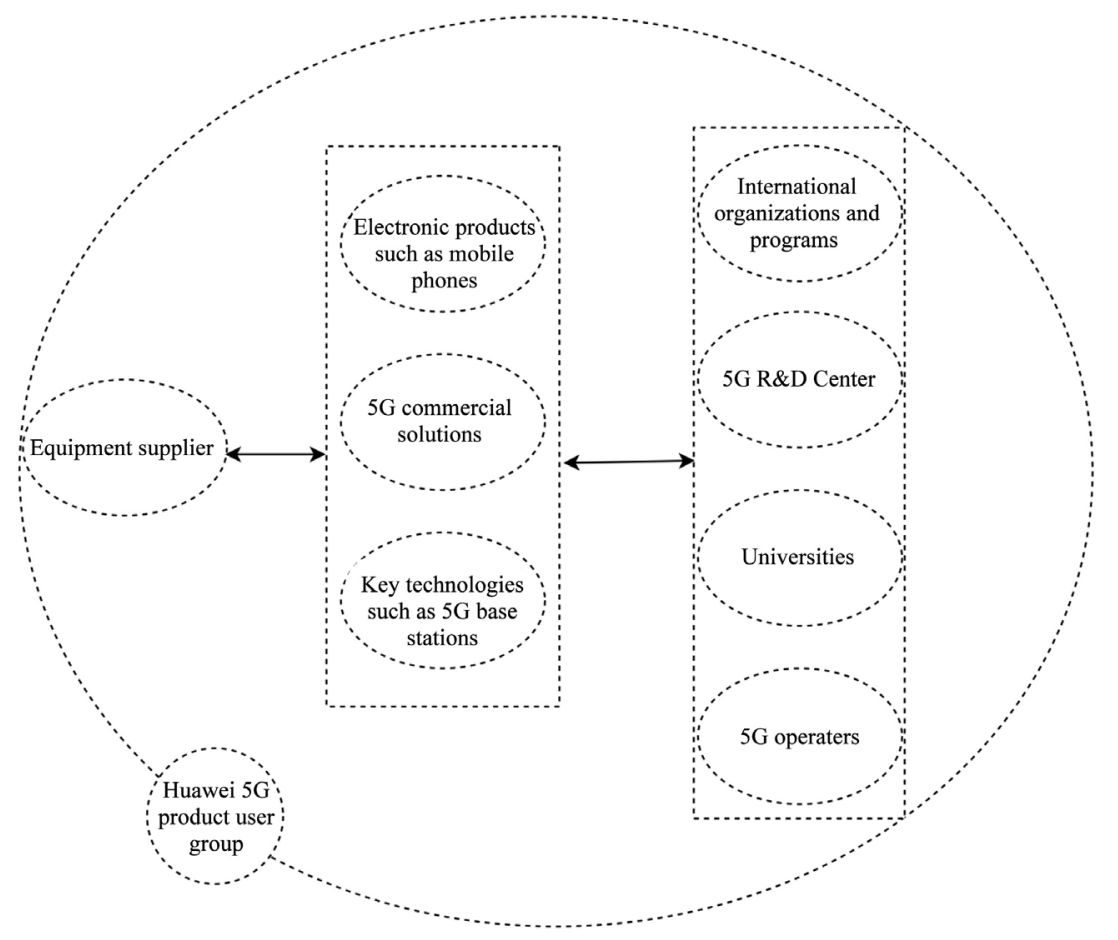

Figure 4. Huawei 5G business ecosystem in the mature and rising stage. 


\subsection{The Structure of Huawei 5G Business Ecosystem}

More than ten years of R\&D investment and establishment of 5G business ecosystem are key factors for Huawei to become a leader in the global 5G market. Huawei $5 \mathrm{G}$ business structure is generally divided into four major categories: operators, enterprises, consumers, and "Cloud + AI". Each part has a clear division of labor, strong professionalism, high cooperation efficiency and significant value creation. This structure fully demonstrates the cohesion of resources and core competitiveness (Figure 5).

1) Huawei operator $5 G$ business ecosystem. Huawei operator $5 G$ business relies on operators with competitive advantages and attracts a large number of 5G-related companies into ecosystem, which is plenty of room for cooperation. Traditional communication services were limited by transmission speed and delay time. Service content is single and costly, which not only fails to meet the new demands of consumers, but also restricts the collaboration methods of participants. Facing the characteristics of $5 \mathrm{G}$ data extremely fast transmission, stable connection and massive IoT, Huawei sliced 5G network, divided resources, and provided packaged products according to different demands with different billing methods. In the past few years, Huawei and Vodafone and other top global operators established joint innovation centers and expert seminars based on common philosophy of pursuing innovation and excellence, aiming to narrow the distance between each other and share benefits. In 2020, Huawei launched "5G Partner Innovation Program", which involves new media, education, medi$\mathrm{cal}$ and other fields. Applying innovation to prosper $5 \mathrm{G}$ ecosystem is a key node for redefining operators, it is also a new cycle of network construction recovery.

2) Huawei Enterprise $5 G$ Business Ecosystem. Huawei enterprise business covers many areas and provides differentiated solutions for different customers. During 5G era, Huawei corporate business extends to more industries, builds a cross-industry communication platform, establishes a targeted network architecture, strengthens dialogue and understanding with vertical industries, and balances the relationship between the goals of business ecosystem members and their own development goals. For example, Huawei, Quectel, China Mobile, Changhong and Sichuan Ailian jointly released 5G modules. Huawei was responsible for main part of module and transferred additional functions to partners in different fields to create profits. Huawei built 5G car ecosystem, cooperating with 18 auto companies such as FAW Group and BYD. Huawei is constantly trying to cooperate in new fields and constantly seeking new opportunities.

3) Huawei consumer $5 G$ business ecosystem. Huawei has formed its own brand market in terms of user payment, service, experience, implementing " $1+$ $8+\mathrm{N}$ " full-scenario smart strategy. Huawei self-produced products represent Huawei's high share of mobile phone market. The advantages are extended to the periphery of tablets, PCs, wearables, smart screens, AI speakers, headsets, VR and car machines. The starting point of Internet of everything is connection, 


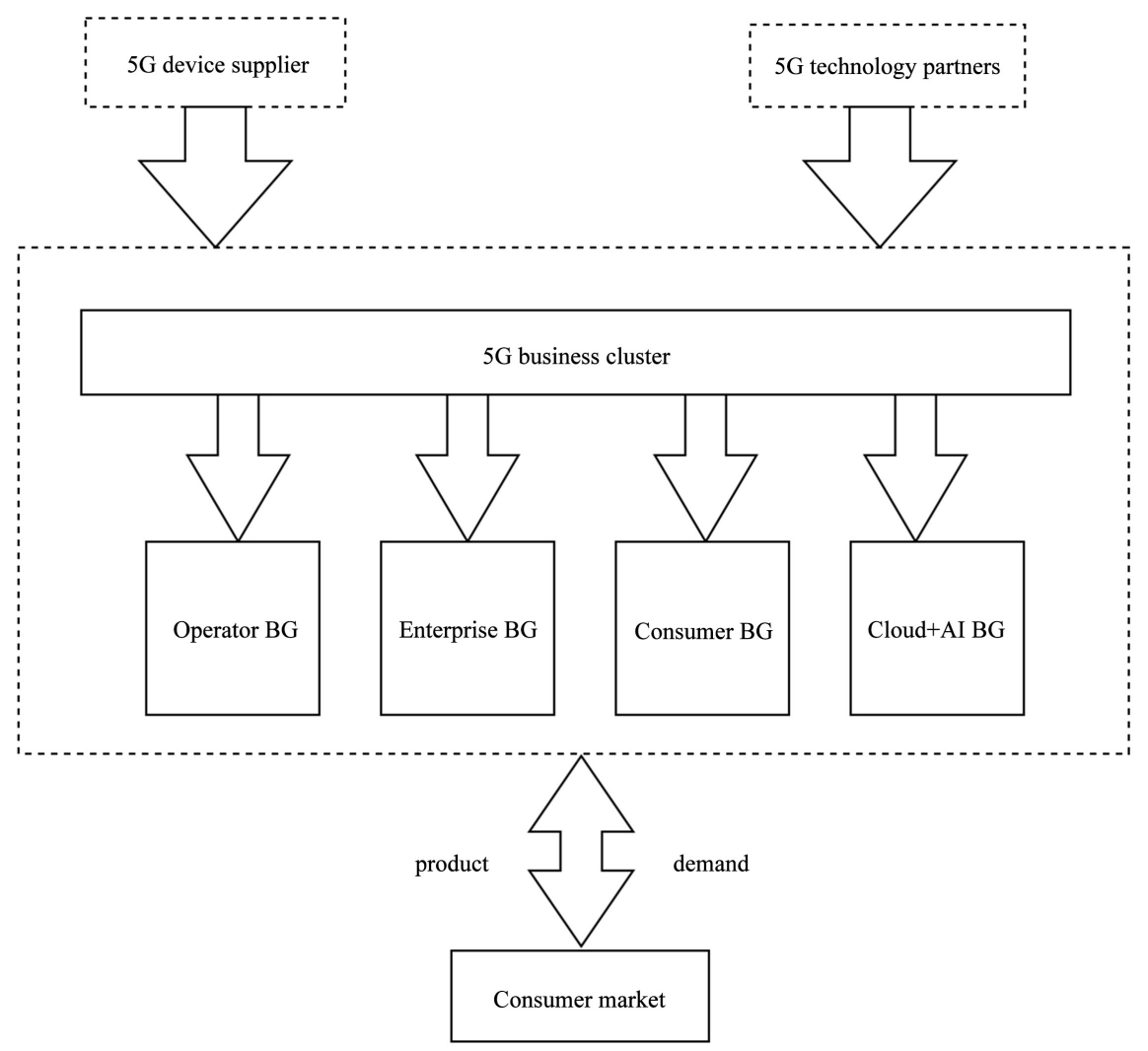

Figure 5. Huawei 5G business ecosystem.

which is also starting point for competition among various manufacturers. Huawei 5G platform responds to market rules and cleverly connects the needs of various industries so that participants can more quickly capture opportunities. For example, Huawei had 5G chip technology and had long-term cooperation with Changxin Technology and Kodali, etc. Based on the needs of consumers, Huawei continuously optimizes and upgrades products and adhere to the R\&D investment of cooperative innovation. Huawei continues to break through consumers' current expectations and leads the trend of global consumer smart terminals. Through the collaborative innovation of two platforms of internal and external ecosystems, Huawei intelligently matches users' demands with terminal service capabilities, so as to enjoy the wonderful experience of smart life.

4) Huawei "Cloud + AI" 5G business ecosystem. In the context of 5G, "Cloud $+\mathrm{AI}$ " business has been put on the agenda in recent years, it provides smart city solutions in areas such as urban operations, unmanned driving, and medical care. As of 2017, Huawei built a Cloud platform with openness and high credibility. In 2019, Huawei launched 5G medical technology cooperation with International Medicine and China Mobile to help telemedicine services in 5G era. In the same year, Tianyuan Technology and Huawei jointly contributed to the application of 5G in remote control of construction machinery. During the novel Coronavirus outbreak, Huawei Cloud "WeLink" opened telemedicine consultations, coordinating office collaboration and interacting in medical teaching. 5G 
high-speed transportation data provided feedback, so that experts could ask for consultation in time and family members could visit remotely to avoid the risk of infection. The integrated development of " $5 \mathrm{G}+$ Cloud $+\mathrm{AI}$ " technology will become a new driving force for industrial development. Cloud provides flexible data storage and analysis, which reduces operating costs. In short, by building a business ecosystem with its own advantages, Huawei continues to innovate and actively develops a Cloud ecosystem of cooperative research development and regional synergy to accelerate the deployment of Huawei's competitive position in $5 \mathrm{G}$ industry.

\section{Discussion and Enlightenment}

\subsection{Enterprise 5G Business Ecosystem Construction Model}

Throughout the literature at home and abroad, the academic circle has formed a relatively comprehensive cognition on the business ecosystem. Although the process and path are different, they pursue the same goal and benefit, and eventually derive into a network structure system with close interaction and stable compatibility. Traditional communication industry has formed a long-term fixed model in face of relatively stable user groups and suppliers, and 5G, as the backbone of the latest mobile communication wave, has the ability to realize three application scenarios of large broadband, low delay and wide connection, which promote cellular mobile communication technology to a new height. 5G technology that truly changes the course of society breaks through original competition pattern and squeezes original profit space. It is difficult to try a familiar field in an unfamiliar edge, but Huawei has gradually explored a business ecosystem suitable for the development of 5G, made clear market positioning, and achieved great success. Based on the analysis of Huawei 5G business ecosystem, we propose that companies need to play a role of resource integrators who can rely on their own advantages to implement a series of strategic changes to corporate platform system and create an internal and external environment in which each organizational link plays its own role (Figure 6).

Enterprise $5 \mathrm{G}$ business ecosystem emerged in networked enterprise organization, and $5 \mathrm{G}$ resources can be quickly transferred in networked structure. We should focus on the broad operational characteristics of the ecosystem as a whole, and define specific indicators of ecosystem structure and ecosystem "health". The evolution literature suggests both that the capacity for creating novel functions is an important measure of system health, and, critically, that the process of integration is an important way of achieving such novelty. The collective impact of network interactions of ecosystem participants on the operating performance of the firm is the fundamental question of ecosystem health. Focusing on the behavior of individual organizations and developing some basic capabilities for successful implementation of strategies for different types of ecosystem strategies is the most important part of networked industry management (Iansiti \& Lewin, 2010). Through enterprise 5G platform system, 5G device 


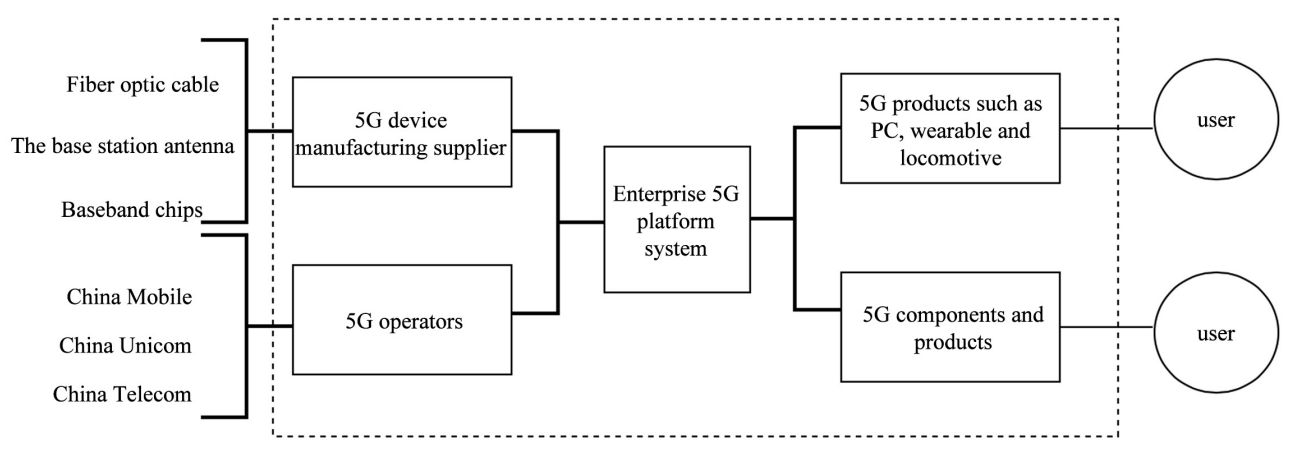

Figure 6. Enterprise $5 \mathrm{G}$ business ecosystem.

manufacturing suppliers provide optical fibers, base stations, chips and other devices. With the large-scale construction of 5G network guaranteed by operators, enterprises can open sales channels in such a layout, which can not only provide ordinary consumers with $5 \mathrm{G}$ products closely related to improving the quality of life, but also create professional 5G components for customized users. In the enterprise $5 \mathrm{G}$ business ecosystem, enterprises play more than one role, it is a rich and diversified existence. Enterprise $5 \mathrm{G}$ platform system closely connects consumers, 5G manufacturing suppliers and 5G operators together. Effective division of labor reduces time costs and resource costs. The process from parts to products is convenient, so that consumers get high-quality products and enterprises get rich returns. Game rules change should re-establish game order, and re-find the game positioning. That's why enterprises are not abandoned by the game circle.

1) $5 \mathrm{G}$ device manufacturing supplier. $5 \mathrm{G}$ MIMO technology can effectively improve transmission efficiency and enhance anti-interference performance. Therefore, the replacement of base station antennas is extremely important. Huawei, Tongyu Communications, Jingxin Communications and other companies have been involved in the field of base station antennas. Different construction methods of $5 \mathrm{G}$ carrier network have put forward higher requirements for professional performance of optical fiber. Chip is the core key for enterprises to provide terminals, and obtaining long-term and stable supply is the most reassuring guarantee for enterprises. Companies such as YOFC and FiberHome focus on manufacturing and supply of optical fiber and cable. At present, Qualcomm and Huawei HiSilicon are the main providers of $5 \mathrm{G}$ baseband chip. The final decision of $5 \mathrm{G}$ device manufacturing suppliers needs to measure transaction cost of external market and operating cost of internal system. There are information exchange barriers between enterprises, and technical performance may not be well-known in the market. Effective communication between enterprises is an important means to break the barriers. It is a crucial strategic decision to make full use of strengths and circumvent weaknesses according to the degree of specialization (Barney, 1999), Make full use of what the enterprise is good at and seek the cooperation of the enterprises that are not good at. For the purpose of seeking advantages and avoiding disadvantages, enterprises will spontaneously organize, interact and cooperate without external or internal 
leaders (Peltoniemi \& Vuori, 2004).

2) $5 G$ operators. Chinese three major operators, China Mobile, China Telecom and China Unicom, are accelerating their deployment by the booming wave of $5 \mathrm{G}$. At the beginning of $5 \mathrm{G}$ commercial use, operators have carried out large-scale network construction. In 2020, 5G networks were fully launched, and the three major operators intensively issued large purchase orders. In addition to continuing efforts in the outdoor 5G Acer Station, indoor 5G micro-base station will become the focus of the three major operators this year. China Telecom and China Unicom will share indoor 5G and accelerate the integrated deployment of indoor scenes. Operators speed up 5G construction and application innovation, carry out $5 \mathrm{G}$ network coverage in some hot areas, cooperate with $5 \mathrm{G}$ enterprises to integrate operators, and build a win-win cooperative development situation for enterprises. 5G enterprises have a bright future. With the application of operators' big data to in-depth analysis of customer needs and classification of user groups, enterprises can quickly and accurately grasp the dynamic changes of the market and provide customers with more precise and standardized products and services. The $5 \mathrm{G}$ business ecosystem will form value networks through which participating companies can achieve competitive advantage (Clarysse et al., 2014). These competitions are inseparable from cooperation, or cooperation is a prerequisite for competition.

3) Enterprises provide terminal products to users, which may be $5 G$ products such as mobile phones, wearables, and motorcycles for mass consumers, or the production of 5G component products required by enterprises downstream in supply chain. Enterprises should take consumer demand as the orientation, examine their living environment and growth state, and establish a 5G business ecosystem that responds to consumer demand and matches the best partners. As consumers' needs, market environment and trend of times are different over time, it shows that the formation of system is not rigid or dull, but a process of cycle, constant change and continuous improvement. Enterprises should always pay attention to innovation, updated technology and demand, and create a development trend of mutual optimization and progress with consumers. The behavior of an enterprise will affect the operation of its business network to different degrees, and ultimately affect the performance of the organization. Every company is like a single species in ecosystem, and will eventually breathe and share fate with entire ecological network.

\subsection{Several Enlightenments for Enterprises to Build a 5G Business Ecosystem}

The various components of the business ecosystem are closely related to each other, and according to the barrel law, the weakness or absence of one part will have a significant impact on the overall development level. Adner believes that by properly assessing ecosystem risks, establishing more realistic expectations, and preparing contingency plans, systems will be more profitable (Adner, 2006). The 5G industry is still on the rise, and the organic support of the mother-child 
system within the business ecosystem is likely to determine the speed of $5 \mathrm{G}$ progress. Therefore, how companies can improve the $5 \mathrm{G}$ business ecosystem is extremely important for their value creation. The relevant enlightenment is as follows.

1) Identify permutations and combinations of risks. There are cooperative innovation risks and adoption chain risks within the ecosystem (Adner, 2014). The risk of cooperative innovation means that the success of innovation depends on the degree of commercialization of other companies' innovations. This is a multiplication concept rather than an average logic, which calculates joint probability rather than independent probability. A full understanding of the true risk probability is an important condition for deciding whether to enter business ecosystem. Enterprises should be based on a broader perspective, classify risk levels, allocate resources appropriately according to value proposition, and define the cooperative vision of participating enterprises to consolidate their weak links in system, so that business ecosystem can survive in a safe and efficient environment. The user in the business ecosystem is a relative concept. If any enterprise refuses to cooperate and destroys the supply order, the final user will be out of the question. It is necessary to ensure that each participating company receives a separate surplus of products or services to achieve a win-win situation for $5 \mathrm{G}$ business ecosystem. In the establishment of $5 \mathrm{G}$ business ecosystem, enterprises should not only consider their own benefits, but also take into consideration the benefits of operators, component manufacturing suppliers and other related enterprises in close cooperation. The value acquisition of individual groups is an important prerequisite for the operation of $5 \mathrm{G}$ commercial ecosystem. Therefore, the construction of enterprise $5 \mathrm{G}$ business ecosystem is by no means a blind act. Logic should be used to dominate actions, risk portfolio factors should be considered in the actual environment, and the internal and external ecosystem of enterprise 5G should cooperate together, so that the value proposition can be realized.

2) Identify company's positioning. In the construction of business ecosystem, more attention is paid to the traditional horizontal route from suppliers to producers, while the vertical connection between complementary enterprises is neglected. This blind spot, however, is the hinge of the decisive business ecosystem and the core link of its value blueprint. To outline the location of each necessary participant, an enterprise needs to know its own position, what role it plays, what the final audience is, what kind of suppliers are needed, and how many intermediaries are involved before the product or service reaches the end user, and what kind of risks they will face. An enterprise needs to objectively evaluate its own strength level and professional ability that is an important factor in measuring the possibility of an enterprise as a needy. In 5G business ecosystem, whether a $5 \mathrm{G}$ leading enterprise or a leader in the $5 \mathrm{G}$ marginal additional field is largely due to the positioning of an enterprise in the network framework. Collaboration with different companies may result in different definitions. Understanding the position of companies in $5 \mathrm{G}$ business ecosystem is the key to 
making a decision (Iansiti \& Levien, 2004). For example, ZTE is positioned in the first camp of $5 \mathrm{G}$ innovation, invested in research and development of $5 \mathrm{G}$ technology, and established a dedicated 5G industry product line. As a supplier of equipment and solutions, it does not directly develop 5G industry application products, but jointly develop with operators and partners in various vertical industries to continuously explore the 5G field and extend its own business breadth. Therefore, when enterprises are participants in building 5G business ecosystem, the chances of success will be greatly improved by understanding the business ecosystem from the perspective of market structure and positioning.

3) Reset business ecosystem. The so-called reset is to accept the limitations and deficiencies of each participating enterprise, to seek a power to combine the imperfections, and to arrange and combine the original enterprises into a new mode of action. Based on the realization form of value blueprint, resetting can be considered from the following five perspectives (Figure 7).

Divide the uniqueness of enterprise, create new individual value and promote the development of overall value. Companies should clearly grasp the characteristics of each participant, that is, what benefits their existence can bring to business ecosystem, whether they have the potential to create profits in long run. The enterprise should be qualitative and precise to achieve the goal of utility maximization. Among 5G companies, there are both dominant and niche companies. The current situation is no longer applicable to the era of the dominant. In fact, professional niche companies are also capable of assuming more responsibility for value creation.

Combine the decentralized state of firms. Spontaneous interactions are the norm in $5 \mathrm{G}$ business ecosystem. Companies need to leverage their competitive advantages, plan and foresee the future. In nature, one of reasons for the longevity of communities is cooperation between species. Similarly, 5G business ecosystem is usually built on a framework with extremely high corporate relevance, and the tacit understanding and communication of partners can be seen as the engine of entire system. The value of $5 \mathrm{G}$ business ecosystem is always more than the sum of its various parts. " $1+1>2$ " is the result of interaction between different companies. This is especially evident in $\mathrm{R} \& \mathrm{D}$. Cooperation and mutual understanding between enterprises on the basis of full understanding and trust will bring the role of business ecosystem into full play.

To move the enterprise to a new location, change the original structure, strengthen the effectiveness, that is, to do the right thing in the right location, adaptability needs to be emphasized. First, companies must have a comprehensive understanding of actual market environment before determining business ecosystem and its environment, and then create a suitable business ecosystem framework. Enterprise boundaries can be defined in terms of 5G applications, and inter-enterprise partnerships can be re-examined. Some enterprises with the ability to create value but inconsistent positioning are faced with the risk of being squeezed out of the market by competitors, so they need to change their mobile position more. 


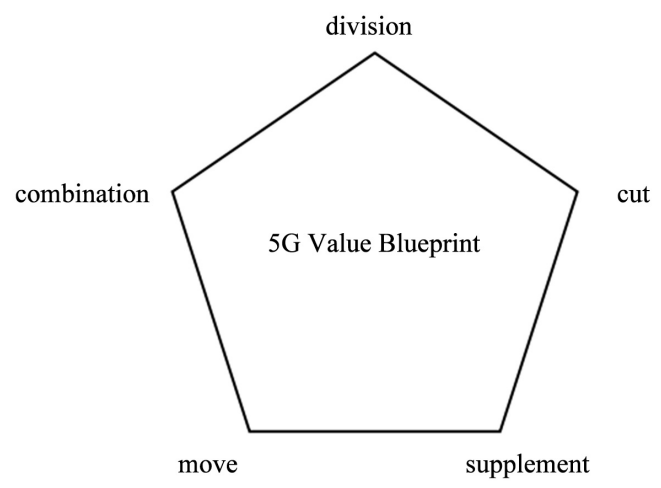

Figure 7. Reset the five elements of $5 \mathrm{G}$ business ecosystem.

Replenish value-creating companies to enter business ecosystem and help establish new connections. Specific issues need to be analyzed in detail. According to the existing characteristics of 5G, enterprises should build their own business ecosystem, which should be highly sensitive and to some extent be able to accept enterprises that are more compatible with themselves at any time. It also needs to have the basic elements for the survival of 5G industry. The ability of new firms to emerge and create new order and coherence will affect the firm's eventual substantial returns.

Cut certain companies to introduce more dynamic companies to business ecosystem. Enterprises should effectively allocate limited resources to more reasonable and more needed links in order to improve the efficiency level of enterprise value creation. The evolution of business ecosystem has been continuing, new connections have been being created and old connections are gradually dying out. 5G related enterprises, which lag behind the development trend of communication and cannot continue to create value, should be eliminated in a timely manner and stop losses in order to prevent the interests of other related enterprises in $5 \mathrm{G}$ business ecosystem from being threatened.

\section{Research Conclusions and Theoretical Contributions}

This paper abstracts and summarizes the theoretical concept of enterprise 5G business ecosystem from the concept of business ecosystem, that is, placed in 5G industry, enterprises with different roles but similar interests interact on the premise of referring to internal and external factors in order to create value maximization, so as to create a situation of collaborative evolution among enterprises. This article has the following theoretical contributions to the research of enterprise 5G business ecosystem. First, it analyzes and describes the construction process of the $5 \mathrm{G}$ business ecosystem of the enterprise, and reviews the development process and characteristics of Huawei $5 \mathrm{G}$ business ecosystem from the perspective of time sequence. Introducing the structure of Huawei 5G business ecosystem, the dynamic trend is obvious. In fact, the internal logic of the $5 \mathrm{G}$ commercial ecosystem is that ecology is calling for the power of "integration". Previous studies tend to be static analysis, which can no longer satisfy the need 
to build an ecological optimization and integration model and enable the 5G industry of all walks of life. Secondly, the experience and enlightenment for perfect integration of enterprise $5 \mathrm{G}$ business ecosystem is better. Academic community has certified the superiority of business ecosystem for a long time, but has failed to answer in depth how to integrate a benign business ecosystem. Huawei 5G business ecosystem has triggered thinking about this issue. Enterprise resource synergies determine how far a business ecosystem can go. Clarifying risks is the prerequisite for consideration, finding the right positioning is the direction of force. "Divide", "combine", "move", "supplement" and "delete" as leverage tools assist in gradual development of enterprise 5G business ecosystem and find feasible solutions to make up for it. It fills the gap of current research.

Huawei $5 \mathrm{G}$ business ecosystem provides the value of case references for the sound operation of other 5G-related companies, and this is a collision between tradition and new trends. Although corporate business ecosystem in traditional research sense recognizes the emergence and efficiency of participants, too much intervention will make business ecosystem lack of vitality, which is not conducive to the progress of business ecosystem in long run. Huawei 5G business ecosystem has fully utilized the autonomous potential of business ecosystem and carried out cooperation from internal to external, which is worth learning from other companies. There are still some shortcomings in this article: the use of Huawei single case study on the construction and experience of enterprise 5G business ecosystem may be constrained by industry characteristics, and there may be other forms of expression in different industries, so the case is descriptive rather than conclusion, awaiting further research.

\section{Conflicts of Interest}

The authors declare no conflicts of interest regarding the publication of this paper.

\section{References}

Adner, R. (2006). Match Your Innovation Strategy to Your Innovation Ecosystem. Harvard Business Review, 84, 98-107.

Adner, R. (2014). Panorama Strategy: The Ecology and Risks of Enterprise Innovation. Trans. Nanjing: Yilin Press.

Anggraeni, E., Hartigh, E., \& Zegveld, M. (2007). Business Ecosystem as a Perspective for Studying the Relations between Firms and Their Business Networks. ECCON, 2007 Annual Meeting, 1-25.

Arikan, E. (2009). Channel Polarization: A Method for Constructing Capacity-Achieving Codes for Symmetric Binary-Input Memoryless Channels. IEEE Transactions on Information Theory, 55, 3051-3073. https://doi.org/10.1109/TIT.2009.2021379

Barney, J. B. (1999). How A Firm's Capabilities Affect Boundary Decisions. Sloan Management Review, 40, 137-145.

Chen, Y. T., Rong, K., Xue, L., \& Luo, L. J. (2014). Evolution of Collaborative Innovation Network in China's Wind Turbine Manufacturing Industry. International Journal of 
Technology Management, 65, 262-299. https://doi.org/10.1504/IJTM.2014.060954

Clarysse, B., Wrigh,t M., Bruneel, J. et al. (2014). Creating Value in Ecosystems: Crossing the Chasm between Knowledge and Business Ecosystems. Research Policy, 43, 1164-1176. https://doi.org/10.1016/j.respol.2014.04.014

Eisenhardt, K. M., \& Graebner, M. E. (2007). Theory Building from Cases: Opportunities and Challenges. The Academy of Management Journal, 50, 25-32. https://doi.org/10.5465/amj.2007.24160888

Hartigh, E. D., Tol, M., \& Visscher, W. (2006). The Health Measurement of a Business Ecosystem: European Network on Chaos and Complexity Research and Management Practice Meeting. In J. P. Xu, M. Yasinzai, \& B. Lev, (Eds.), The 6th International Conference on Management Science and Engineering Management (pp. 1-39). London: Springer-Verlag.

Iansiti, M., \& Levien R. (2004). Strategy as Ecology. Harvard Business Review, 82, 68-81.

Iansiti, M., \& Lewin, R. (2010). Keystones and Dominators: Framing the Operational Dynamics of Business Ecosystems. Boston: Harvard Business School Press.

Lansiti, M., \& Levien, R. (2004). The Keystone Advantage: What the New Dynamics of Business Ecosystems Mean for Strategy, Innovation, and Sustainability. Boston, MA: Harvard Business School Press.

Liu, G., \& Xiong, L. F. (2013). Dynamic Consumer Demand Response, Enterprise Boundary Selection and Business Ecosystem Construction-Based on a Case Study of Apple Inc. China Industrial Economy, No. 5, 122-134.

Moore, J. F. (1993). Predators and Prey: A New Ecology of Competition. Harvard Business Review, 71, 75-86.

Moore, J. F. (1996). The Death of Competition: Leadership and Strategy in the Age of Business Ecosystems. New York, NY: Wiley Harper Business.

Palattella, M. R., Dohler, M., Grieco, A., Rizzo, G., Torsner, J., Engel, T. et al. (2016). Internet of Things in the 5G Era: Enablers, Architecture, and Business Models. IEEE Journal on Selected Areas in Communications, 34, 510-527. https://doi.org/10.1109/ISAC.2016.2525418

Peltoniemi, M., \& Vuori, E. K. (2004). Business Ecosystem as the New Approach to Complex Adaptive Business Environments. In M. Seppä, M. Hannula, A. M. Järvelin., J. Kujala, M. Ruohonen, \& T. Tiainen, Frontiers of E-Business Research 2004 (pp. 267-281). Tampere: University of Tampere.

Ritala, P., \& Almpanopoulou, A. (2017). In Defense of 'eco' in Innovation Ecosystem. Technovation, 60-61, 39-42. https://doi.org/10.1016/j.technovation.2017.01.004

Rowley, J. (2002). Using Case Studies in Research. Management Research News, 25, 16-27. https://doi.org/10.1108/01409170210782990

Sun, C., \& Wei, J. (2019). Research on the Structure and Collaborative Mechanism of Enterprise-level Innovation Ecosystem. Studies in Science of Science, 37, 1316-1325.

Tan, Z. J., Wei, W., \& Zhu, W. X. (2019). The Construction and Value Creation of Business Ecosystem-A Case Study of Xiaomi Intelligent Hardware Ecological Chain. Management Review, 31, 172-185.

Tong, Y. Q., \& Yang, Y. J. (2019). Research on Ali Business Ecosystem and Platform Operation Mode. Science and Technology Management Research, 39, 254-260.

Xu, S. (2019). 5G Contributes to High-Quality Development of China's Economy. China Economic and Trade Guide, No. 17, 51-54.

Yin, R. K. (2013). Validity and Generalization in Future Case Study Evaluations. Evaluation, 19, 321-332. https://doi.org/10.1177/1356389013497081 
Zhang, Y., Liu R. H., \& Chen H. Q. (2018). The Formation Path of Platform Enterprises' Ecological Advantages in the Business Ecosystem-A Longitudinal Case Study Based on JingDong. Economics and Management Research, 39, 114-124.

Zott, C., Amit, R. H., \& Massa, L. (2011). The Business Model: Recent Developments and Future Research. Journal of Management, 37, 1019-1042.

https://doi.org/10.1177/0149206311406265 